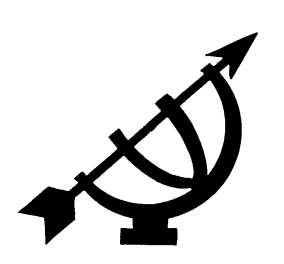

\title{
Understanding beyond language: perceiving meaning in reality
}

\author{
C.D. Scott \\ Department of Philosophy \& Systematic Theology \\ College of Human Sciences \\ University of South Africa \\ PRETORIA \\ E-mail: scottcd@unisa.ac.za
}

\begin{abstract}
Understanding beyond language: perceiving meaning in reality
\end{abstract}

This article is an attempt to develop a counter-argument to the contention that meaning is bound by language. Locating itself within the realist ontology of language developed by Saint Anselm of Canterbury, it will be argued that language comprises representations of entities perceived both extra to the perceiver and through introspection. Thus, a language game cannot be a closed system in the sense that by its very existence representations of extralinguistic being are contained therein. If truth is defined as that which is the case, the task of the perceiver becomes apprehension of being beheld without the cloud imposed by symbols: representations are not what they represent, instead they serve as windows onto a view of what is. Following exploration of psychological studies on contemplation, it is argued that it is in desymbolised moments of attentive awareness of being that meaning, unfiltered by the representativeness of language (and indeed, other symbolic systems), can arise. It will be proposed that in contemplative traditions, being is not reduced in perception, and the moment of meaning comes to the fore in the engagement and encounter with being.

\section{Opsomming}

Begrip verby taal: gewaarwording van betekenis in die werklikheid

Hierdie artikel is 'n poging om 'n teenargument te ontwikkel vir die standpunt dat betekenis ingeperk word deur taal. Deur die 
argument binne die werklikheidsontologie van Sint Anselmus van Canterbury te plaas, sal geargumenteer word dat taal representasies bevat van entiteite wat buite die waarnemer en ook deur introspeksie waargeneem word. 'n Taalspeletjie kan dus nie 'n geslote sisteem wees sodat deur sy blote bestaan representasies van buite-linguistiese syn daarin vervat is nie. Indien waarheid gedefinieer word as dit wat is, word die taak van die waarnemer bewuswording van syn sonder die wolk wat deur representasie opgelê word. Representasies of simbole is nie dit wat hulle voorstel nie; hulle dien eerder as vensters op dit wat is. In die lig van psigologiese studie oor nadenke word geargumenteer dat ongesimboliseerde oomblikke van aandagtige bewustheid van syn, betekenis na vore laat kom wat nie deur die representatiewe aard van taal (en inderdaad ook ander simboliese stelsels) gefiltreer is nie. Die stelling word gemaak dat in kontemplatiewe (nadenkende) tradisies die syn nie gereduseer word tot gewaarwording nie, en dat die oomblik van betekenis na vore kom in die betrokkenheid by en die ontmoeting met die syn.

\section{Introduction ${ }^{1}$}

This work explores the obstacle that language-bound humans face that renders them unable to grasp reality unhampered by the limits of linguistic categorisation. The aim is to counter the now commonplace assumption that language mirrors reality, rather than directing humans into being through transcendence of the symbolic system. The language-bound argument opposes the contemplative experience wherein unity with being is obtained. It is the latter for which this article ultimately argues. As an exercise in multidisciplinary research the boundaries of the author's research will be formed by philosophy, theology, linguistics and cognitive science.

The work proceeds by an analysis of the problem. The ontology that will be employed, that of Saint Anselm of Canterbury, will be the lens through which the study is carried out. His realist ontology will be explained prior to our consideration of various "language-bound" positions (among these Lakoff, Johnson, Rorty and Fodor). The argument will thence be proposed that human beings are not "language-bound" due to language's evocative nature and the structure of language games. Instead, the extralinguistic partial apprehension of reality will be argued for.

1 The author acknowledges the constructive comments of Hildegard van Zweel, Department of Linguistics, UNISA throughout the development of this article. 


\subsection{Background}

Saint Anselm's realist ontology draws attention to the complex relationship between reality and language. In his philosophical thinking, truth is located in the existence (being) of the signified, rather than in the signifier (symbol/representation). Anselmian realism posits an ontological separation between signifier and signified.

If it is indeed the case, this ontological separation could restrict human linguistic activities to language games with meanings established by practice, rather than in correspondence to extra-linguistic being.

\subsection{Problem statement}

In the light of Saint Anselm's proposition that language can never provide humans with an adequate account of truth or being, as truth is only contained in the entity of which the symbol is but a representation, an important question arises. To what extent are human beings "bound" by language? Research into this question will assist in determining to what degree truth or being can be obtained by humans. If language indeed has its limits of explanation, alternate paths of access to being need to be sought.

\subsection{Hypothesis}

The argument will be made that, although human experience is partially informed by language, the evocative nature of language aids in directing the employer of the linguistic entity beyond the confines of linguistic categorisation. In this process the human being is able to capture truth/being itself. Moreover, it will be proposed that an unmediated grasp of Truth/Being can only be achieved through contemplation.

\section{Saint Anselm's realist theory of truth}

"When is a linguistic statement true?"2 A statement is true when it states what is the case (Anselm, 2000:165). 3 Truth subsists in the

2 This is a revision of the Anselmian question: "When is a statement true?" (Anselm, 2000:165.)

3 We extend the meaning of "statement" to refer to mental representations perceived through sensory experience or through introspection developed into a collection of cognitive symbols. 
truth of the case - object, event, or thought - signified by the statement, and not in the statement that represents reality (Anselm, 2000:166). ${ }^{4}$ An inductive inference is made when the nature of truth is deliberated: statements are always true when they signify what is rightly the case (Anselm, 2000:168). ${ }^{5}$ Whatever is rightly the case is that which exists (Anselm, 2000:168-170, 173). Therefore an entity is rightly signified when what is signified is the being of the entity (Anselm, 2000:174).

If a statement is declared true, it directly claims that the signified exists. 6 Consequently, we should ponder the cause of existence, that is, the cause of the statement's truth. Anselm places truth in the context of the cause (or source) of all that is. If the supposition is made that truth had both a beginning and an end in time, it would be true to argue that truth existed neither before or after its existence (Anselm, 2000:164-165).

... [E]ven before truth came to be, it would have been true that there was no truth; and even after truth had come to an end, it would still be true that there would be no truth. But it could not be true without truth. (Anselm, 2000:165.)

To propose that truth exists when truth is not, is contradictory. Hence, Anselm concludes: "... truth cannot be confined by any beginning or end ..." (Anselm, 2000:165). Truth has an eternal nature because if at any moment one can declare a statement to be true, truth exists. The truth of a statement is conditional upon its stating the case. If truth is eternal the cause of the truth must be eternal, too (Anselm, 2000:180). This cause of truth lies not in the temporal entity signified in the representation of the statement (which is only true in as much as the temporal entity exists), but in truth as an eternal entity. ${ }^{7}$

4 " $[T]$ he truth of something true is in that true thing. But the thing stated is not in the true statement, and thus must not be called its truth; rather, it must be called the cause of the statement's truth." (Anselm, 2000:165.)

5 That is if they signify what is, is, and what is not, is not (Anselm, 2000:168).

6 Following the definition of truth as that which rightly signifies.

7 This abstraction emphasises that a true statement (i.e. a statement which rightly signified what is in fact the case) cannot but be true and is always true in so much as it participates in truth. "... [I]f truth could in no respect fail to be in this statement (given the statement), then it follows that Truth which is the supreme 
It can be argued from the relativist perspective that there are multiple irreconcilable truths, rather than a singular eternal truth (Anselm, 2000:187).8 Many independent "rightnesses" (truths in signification) would direct to the existence of multiple entities which are rightly signified in true significations, true by their representing what is (Anselm, 2000:187).

In response, however, it can be said that the existence of the particular entity signified is not contingent upon the signification (Anselm, 2000:188). Even if the signification does not occur, this does not remove the potential for a right signification to occur: rightness continues to be (Anselm, 2000:188). Rightness exists not in the signification made, but the signification may be said to be right (truthful) because it is made in accordance with being (Anselm, $2000: 188$ ). From an Anselmian perspective being is located prior to perception, signification, and understanding. Being has the potential to be signified and exist, regardless of whether or not the signification is made. Hence, while there may be many particular truths (rightnesses in significations) that the signification does not alter, the rightness of the entity logically entails that truth is not rightness in terms of signification, but rightness in terms of the being of the phenomenon signified (Anselm, 2000:189). The rightness emphasised by St. Anselm transcends particularities, for it is not so much concerned with signification but with the abstract concept of rightness. In referring to truth as representative of what is, Anselm declares "... the rightness of all things ... is one and the same" (Anselm, 2000:189). ${ }^{9}$ Moreover, if the rightness of things is one it is necessarily the case that in these truth is to be found (Anselm, 2000:190).

cause of this statement's truth cannot be understood to have an end" (Anselm, 2000:180).

8 "For when what is is signified to be, or when what-is-not is signified not to be, then the signification is correct, or right, and (assuredly) rightness exists without which the signification could not be right." (Anselm, 2000:187.)

9 Anselm, 2000:189:

$\ldots$ if it is only when things are in accordance with what they ought to be that rightness is in those things which ought to have it, and if for them to be right is only [for them to be in accordance with what they ought to be], then it is evident that the rightness of all these things is only one. 
From a scriptural perspective, God is truth (Anselm, 2000:164).10 Could God as truth thus be affirmed as in all things which are true (in all that is) (Anselm, 2000:164)? Anselm unapologetically identifies God as the "Supreme Truth", and with this delineation providing for him the truest understanding of the nature of truth (Visser \& Williams, 2004:204-205). Whatever is, is true, and whatever is true is so only because it participates in what truth is rightness (Anselm, 2000:174). The assumption made from the definition of God as truth, is that all that is, is contingent upon the Supreme Truth (Visser \& Williams, 2004:210). This - Being itself - is uncaused, for there can never be a moment when a truth was not true in that if the statement's truth always is, then the cause of the statement's truth must always exist (Anselm, 2000:180). ${ }^{11}$ Nevertheless, the issue of the existence of the Supreme Truth remains. There is no empirical evidence for its existence, yet without a causal matrix, is there reason for the existence of anything?

Anselm's theory of truth, while theological, guides our attention to an important philosophical problem: "... few consider the truth which is in the being of things" (Anselm, 2000:177-178). Truth is extended to being through the argument that, by existing, entities reveal truth: "... by the very fact that they are, they declare that they ought to be" (Anselm, 2000:178-179). This is a meta-analysis of the individual truth signification whereby an abstraction is created to understand truth. Indeed, Anselm draws a universal conclusion from his movement of individual signification to truth in being, and being's contingency. He proposes that

[r]ectitude does not depend on the things in which there is rectitude: there is one never-failing, unchangeable rectitude for all things in which we say there is truth or rectitude (Visser \& Williams, 2004:217).

If rightness of the signified does not depend upon the signifier but rather on truth as being, then an ontological separation exists be-

10 See John 14:6. As an article of faith God's identification as "truth" is possible to reason over while remaining improvable. If truth is defined as rightness where rightness resides in signification of what is, i.e. being, the God who is identified with truth is intimately connected with the problem of existence: the metaphysical question of the contingency of everything that is returns, and the God who is truth is conceived as the ground of all being.

11 "Indeed, the truth of the statement could not always be unless its cause always were." (Anselm, 2000:180.) 
tween what signifies (e.g. the word [symbol] apple), and the object of the signification (e.g. an apple). What signifies - in this instance the word-symbol - and the reality being signified are not the same. While apple leads to understanding of a particular component of reality if rightly signified, it does not reveal (without further exploration) the fullness of the apple's "apple-ness" - all that forms its identity, such as greenness, crispness, tartness, et cetera - which collectively make up rightly what the apple is. What determines the apple's truth is the "... rightness which always exists ..." (Anselm, 2000:188-189).12 Visser and Williams (2004:219) succinctly sum up Anselm's theological theory of truth:

Something has rectitude because it accords with its purpose. Something receives its purpose from whatever caused it. God causes all things. So whatever is said to be true is true in virtue of being caused by God in accordance with his will, and God is Truth because He causes all things ...13

While one may disagree with the faith foundation of the argument which fails without the signification of God as truth, Visser and Williams highlight the ontological nature of truth for which Anselm is arguing. Anselm challenges us to comprehend what is held as true as more than what is declared in linguistic categorisation of phenomena. For him, truth exists only because it has being rather than because it is perceived and categorised by the agent (Visser \& Williams, 2004:219).

\section{Are human beings language-bound?}

Anselm's realist ontology directs beyond symbolic systems. Contrary to this point of view are arguments wherein language is proposed to be in sum what can be known - the only means through which anything can be known, or the human being's experience of reality as indubitably filtered by the linguistic categories at our disposal. We identify these as language-bound arguments.

12 "The rectitude or truth of signification does not have its being through signification but is altogether independent of signification." (Visser \& Williams, 2004:216.) 


\subsection{Language-bound arguments}

\subsubsection{Lakoff and Johnson}

Lakoff and Johnson argue that the human being's employment of concepts and categories in language emerges from the human being's embodied, subjective experience of reality (Lakoff \& Johnson, 1999:17). Meaning has its origin in the embodied form: only through the body can perception and comprehension of self and environment occur (Lakoff \& Johnson, 1999:17). Is it, therefore, implied that what is real is only that which has been filtered by our embodied perception (and, by extension, through linguistically grounded understanding)?

For Lakoff and Johnson, without the categorisation of what is experienced outside the self, from the perspective of the self, even the amoeba would not be able to discern the nutritious from the not nutritious (Lakoff \& Johnson, 1999:17). 14 Categorisation - the division of reality into understandable chunks - is fundamental to survival (Lakoff \& Johnson, 1999:18). Hence,

[w] cannot, as some meditative traditions suggest, 'get beyond' our categories and have a purely uncategorized and unconceptualized experience (Lakoff \& Johnson, 1999:19).

Language is possible because of the conceptual structure made available to humans from perceptual categorisation (Lakoff \& Johnson, 1999:21). But can Lakoff and Johnson's argument be accepted?15 It is important to keep in mind that the real is more than what the human being categorises, for the human being is only part of what is. If perception limits the knowable, is that sufficient a foundation to assert that the real is not? The authors clarify:

... human concepts are not just reflections of an external reality, but ... are crucially shaped by our bodies and brains, especially by our sensorimotor system (Lakoff \& Johnson, 1999:22; italics - CDS).

Lakoff and Johnson's position is weakened in qualifying that concepts - the product of human perception - are partially the fruit of experience of an external reality. This reality transcends the human

14 The assumption is made that the amoeba can discern and has self awareness.

15 "Our categories of things in the world determine what we take to be real: trees, animals, people, buildings, and so on." (Lakoff \& Johnson, 1999:21.) 
being, for in its perception there is correspondence between perceiver and object perceived. While the perceptual information is somewhat the result of the human embodied state - which includes language - the human being's conception of what is real is not the sole product of humanity's systems of categorisation, such as language.

Agreed, "for real human beings, the only realism is an embodied realism" (Lakoff \& Johnson, 1999:26). However, this should be carried into the broader context of the human being. Individual conception of reality is not the only conception: commonalities exist between individual perceptions, as evident in communication where shared understandings emerge. Still, the individual's understanding is always from the subjective perspective which includes the cultural, linguistic, social, religious, historical and political background of the perceiver. In an act of shared meaning, there is a synthesis of both the subjective and the intersubjective. Moreover, in perception an interaction arises relating the subjective experience of reality with the external reality itself. A form of clarified realism should be embraced: the "real" - as perceived - has multiple dimensions; the individually perceived (subjective) and that of which the individual is but one dimension (objective). Here then, the discussion of the "real" takes into cognisance both the subjective, epistemological dimension of human experience, and the fundamental, ontological component of reality.

If all that can be known is from the embodied, subjective perspective, is it implied that the individual perceiver has a privileged perceptual position? Some varieties of subjectivism argue that shared meanings are impossible. C.I. Lewis (1929:116), for instance, claimed that "... knowledge or the communication of ideas is dubious or impossible in the light of the subjectivity of sense". Wilder explains that, since for Lewis meanings are considered as "... abstract mental entities ..." there is no surety of the sharedness of meanings (Wilder, 1971:27).16 Lewis conceptualised meaning as present in individual experiences (knowledge and thoughts) as well as in words. Moreover, he understood meaning as specifically present in concepts, though it is in terms of concepts that he introduces the communal dimension of meanings in defining a concept as the

16 It should be noted, however, that embodied realism does not take subjectivism to Lewis' extreme: shared meanings are possible, although always from the perspective of the subject. 
particular variety of "... meaning which must be common to two minds when they understand each other ..." (Lewis, 1929:70). The subjectivist may argue that because meaning is an individual mental construct it is impossible to grasp what anyone else means entirely (Wilder, 1971:28). At a less extreme degree, meanings could only be shared partially by people who have similar characteristics, contexts, et cetera, thus remaining relativistic. The subjectivist and the relativist appear doomed to the consequences of closed language games.

People brought up in different cultures will speak different language-games, with different rules from ours. They think of the world from within their own language and culture; in some cases they have different interests and values, in which cases their culture leads them to direct their attention to different sorts of things from those salient in our culture. (Kirk, 1999:98.)

From within a language game truth is determined by what is accepted by the players of the game. Truth is consensus within a game, provided that truth is not determined by anything more than the game played (Kirk, 1999:98).

\subsubsection{Rorty}

Building on the later Wittgenstein and Donald Davidson, Richard Rorty agrees with the removal of "... the central presupposition of Philosophy ..." in terms of language, namely that sentences are true when they correspond with the way things are (Rorty, 1982:xviii). Rorty was particularly critical of theories which purport that the human mind is "a great mirror" in which representations of external (and internal) realities are accurately or inaccurately represented (Rorty, 1979:12). The assumption that representations are possible arises from the presupposition that knowledge of anything is achievable (Rorty, 1979:9). Regarding particular representations, such as linguistic terms, Rorty (1989:4) states: "... there is no sense in which any of these descriptions is an accurate representation of the way the world is in itself". This is Wittgensteinian.17 Any representation does not accurately represent the world-as-it-is to the employer of language (or any other cognitive system). The meaning is not rooted in "reality", but in the convention of how the word is used (Rorty, 1989:4). "... [W]here there are no sentences there is no

17 " $[\mathrm{A}]$ word hasn't got a meaning given to it as it were by a power independent of us. A word has a meaning someone has given to it." (Wittgenstein, 1960:28.) 
truth, that sentences are elements of human languages, and that human languages are human creations ..." necessitates for Rorty (1989:5) the fact that there is no truth outside the linguistic statement.

Only the players of language games, composed of sentences, can hence possess meaning (Rorty, 1989:18). It follows that meanings within language games function in closed systems whereby meaning is determined through consensus among players of the game, rather than correspondence to any dimension of "reality" external to the language game. Hence, Rorty removes the possibility of testing representations with extra-symbolic entities. If meaning is only possible within language games (and from language usage), languages can be compared with languages, but never with anything else (Rorty, 1989:20).

If the mind is not a mirror capable of holding intrapersonal experiences as well as representations of the reality external to the perceiver, then Rorty's conclusion that meaning can only be contained within sentences as determined by the use of language, is perfectly sound. The language game is thus a closed system of reference. However, even in a reality wherein meaning is closed in language games there are multiple variables. In the first case, if there is shared meaning as a result of multiple players of a language game, it necessitates a context within which the game is played. Moreover, if the players of a language game have shared meanings, at what point do their experiences of their context cease and the closed language game begins (being played in isolation of the context)? The influence of the language game upon the context and more importantly for cognitive theories of representation, the influence of the context upon the language game seem not to be quite so apparent.

The arbitrary assignment of labels to particular entities and experiences from within language games does not have great relevance to the issue at hand. A relation between signifier and signified evolves through the usage of the term. With this one agrees. That the relation is arbitrary is for this study not fundamental. Rather, that the term comes to relate meaningfully to extralinguistic entities (whether internal or external to the perceiver) would indicate to some degree that language games are not completely closed systems in their occurring in relation to a broader context and in relation to related entities. 


\subsubsection{Fodor}

A further language-bound theory is that of Jerry Fodor (2000:53), who proposes the analogical argument that thought is language-like and thus representational. At the heart of Fodor's hypothesis is that a psychological model of cognition has to be representational, for "computation presupposes a medium of computation: a representational system" (Fodor, 2000:51). While this may beg the question, Fodor (2000:51) develops his theory starting from an ambitious attempt to demonstrate that all mental processes have to occur within a representational system.

The theory of the "Language of Thought" proceeds from a consideration of the psychology of choice in an agent's moral decisionmaking process: when an agent can represent possible situations, behaviours, and potential consequences to the self the agent can take a moral decision (Fodor, 2000:53). Moreover, within this representation is also a judgement of the kind of behaviour which could be enacted; were this representation removed one could not explain the motivation for particular moral actions (Fodor, 2000:53). In this, Fodor (2000:53) discerns evidence of the computation of an agent's possible moral action occurring to the agent from within a representational system, for without a representational system computation cannot occur. Indeed, he goes as far as declaring that "I might as well have said that the model presupposes language", as Fodor (2000:53) draws out similarities which exist between representational systems and language.18 Firstly, an infinite number of representations form both part of a representational system and of language of which there is no limit to the possible number of representations. Secondly, both reference to entities and truth regarding representations (significations) form part of the representational system and of language (Fodor, 2000:53-54).19 In addition to moral decision-making, Fodor (2000:55) views concept-learning and perception as computational and thus as representational processes. Concept-learning is representational, for in the grasping of a concept a phenomenon is considered and computed in addition to a relationship being developed between a phenomenon (stimulus) and

18 The assumption of language is problematic, as without it the language of thought remains unproven and circular in argumentative nature.

19 Fodor is defending a realist correspondence theory in his representational system: “... ' $D$ ' describes what ' $a$ ' refers to if ('Da' is true if $a$ is $D$ )" (Fodor, 2000:54). 
the content of the representation (Fodor, 2000:55-56). Similarly, perception involves computation, for in the perceptual process recourse is made to past experiences to grasp experienced phenomena, because past experiences are projected onto what is perceived and a reasonable choice is made in terms of available hypotheses (Fodor, 2000:59).

[P]sychological processes are typically computational and computation presupposes a medium for representing the structures over which the computational operations are defined. (Fodor, 2000:63.) ${ }^{20}$

The Language of Thought hypothesis describes the nature of thought as language-like. But, if language undergirds computation, is the argument that there is an objective way in which reality is apart from the perceiver negated by thoughts having a represen-

20 The Fodorian theory that all thoughts are computational finds its source in his development of a "Representational Theory of Mind" (RTM) and in the influence Turing's notion ("... that thinking is a kind of computation ...") had upon Fodor (1998:10). Ontologically, mental representations precede propositional attitudes, while these in turn precede natural languages in terms of intentionality (Fodor, 1998:7).

[F]or each event that consists of a creature's having a propositional attitude with the content $P$ (each such event as Jones's believing at time $t$ that $P$ ) there is a corresponding event that consists of the creature's being related, in a characteristic way, to a token mental representation that has the content $P$ (Fodor, 1998:8)

$P$ could only be conceived as true if there is correspondence in the "tokening-ofa-mental-representation" (Fodor, 1998:8). For the language statement to be, the constituting proposition must hold representational content (Fodor, 1998:9).

In keeping with his "Representational Theory", Fodor (1998:10) conceives that all thoughts are computational. His (Fodor, 1998:9) reasoning relates to the aforementioned idea that propositional content requires a representational undergirding. This is because all cognitive representations are symbolic (in that they symbolise or represent an entity beyond the symbol), moreover, these "... symbols are physical objects with semantic properties" (Fodor, 1998:10). By "semantic properties" it is implied that symbols have meanings. Computations, then, for Fodor (1998:10) are the causal relationships between symbols, which continue to uphold the semantic properties of the symbols in relationship. The symbol of "red" is not a symbol which functions in isolation from others associations arise (Fodor, 1998:10). Hence, the symbol "red" is associated with the symbol "colour", or perhaps with that of "blood", through the computational process. The theory of thinking understood as computation only requires that symbols possess meaning such that relationships between other meaningbearing symbols can occur (Fodor, 1998:11). If, Fodor argues, a symbol is representational, it necessarily possesses semantic properties, and thus it will be able to be in relation to other symbols computationally. 
tational structure? The Anselmian theory of truth emphasises ontology over epistemology, for all knowledge is tainted in symbol.

Fodor's Language of Thought hypothesis could add to the possibility of transcending language in such a way that one might have insight into being. If the only way through which one is able to exist as an embodied being is through and with thoughts that are structured in a linguistic manner, and if representations constrict ontology, then contemplative moments (which will be evidenced in the later psychological and linguistic studies) do in fact guide us to a better grasp of what is outside linguistic boundness.

\subsection{More than language}

While these are influential arguments, it can be argued that human beings are not language-bound.

\subsubsection{The evocative nature of language}

Rudolf Botha (2003:45-46) developed a non-reductionist ontology for language. Among the capacities which he affords language is its underlying of perception (Botha, 2003:206). Only through the human being's perceptual ability can understanding of the context within which the human being finds herself occur. If language plays a fundamental role in perception, then it is essential in terms of understanding the extralinguistic reality. As Chomsky (1982:6; italics - CDS) notes:

... one can conceive of the study of language as being one possible paradigm for the investigation of the nature of knowledge, the nature of human knowledge, and the problems of a priori knowledge.

Language is a single means to knowledge; there is more to being than language. This is upheld in embodied cognition models which theorise that language is supported by mental representations of experienced entities (Evans \& Greene, 2006:240-241).

During perception, symbols of neurons in sensory-motor regions of the brain capture information about perceived events in the environment and in the body. (Barsalou, 1999:582.) 
The external reality is not only the context within which perception and language occur, but is prior to perception and cognition.21 Experience of being does not end in representations that mediate perception of sensory experience, mental states and cognition. As a symbolic representational system (cognition) language evokes the reality (that of which the players of the language game are a single part) to which the symbol points and by which the symbol is formed through perception (Spader, 1998).

There is a prima facie difference between poppies, syringes, automobiles, human bodies, and so forth and the signifiers that designate and refer to them ... The philosophical mistake of semiological reductionism is the systematic refusal to accommodate this prima facie difference within the sphere of human experience ... the effects of the reduction culminate in a loss of the evocative ... the capacity of language to awaken in ourselves the quality of another's experience (Dillon, 1995:166).

The human being can never be totally language-bound when the linguistic entity employed relies on perception for the raw data which is employed for cognition to occur.

[T] is not to have the hearer repeat correctly the counters, see, green, and table, but to have him look in the same direction and to duplicate the experience of seeing a green table, whether in fact or in imagination. The truth is not in the statement but in the experience to which it directs us. The hearer has grasped the truth when he is in turn able to say, 'I see it, too', not when he can repeat it correctly. (Kohak, 1984:64.)

Language leads beyond its confines in its symbols having partial relation to extrasubjective entities. Yet, symbols are not the reality they represent. They are representations of real dimensions of reality interpreted by human beings in cognition, as informed by numerous influences.

21 Perception is the capacity to process information from the senses and from states within the body, while cognition refers to the processes of perceptual information becoming accessible to the mind through the development of representations of perceptual information (Evans \& Greene, 2006:240). The linguistic entity is one component of the process of cognition through which representations are formed. 


\subsubsection{The structure of language games}

When counter interpretations of the same phenomenon expressed in language games arise, so too does the problem of how the truth of any singular knowledge claim can be established. Kirk (1999) provides the example of two communities making opposing claims concerning the size of the sun relative to the moon. To measure the magnitude of either requires theories (i.e. cultural constructions), but the real is what conforms to particular cultural practices, as contained in a language game.

If the argument works, then truth and falsity, and with them reality itself, depend on what we think, on our point of view. So realism is wrong and we have to accept anti-realism. (Kirk, 1999:99.)

Problematic, however, is the scientific enterprises' continued testable advancement of what it is possible to know despite cultural affiliations. Results of scientific experimentation are not culturally relative, although interpretation may be. Remaining in cultural ghettos of thought thence is a refusal to acknowledge the real for the sake of saving the language game's meaning. The accuracy of a scientific measurement is relevant only within the discourse of a particular scientific community's acceptability of these measurements in its particular language game (Kirk, 1999:101). This implies that the language game played is done so in an extended understanding of culture, where the practice of science becomes the cultural group within which the game is played.

If a particular science is construed as a language game, then the cultural limitations on the scientific endeavour necessitate that what is presented as reality is only real in terms of what is accepted by a particular group's convention (Kirk, 1999:101). The scientific experiment in practise, however, counters this relativism. Science always attempts to unearth the way that things are through scientists' endeavouring, at the very least to aim for objectivity in their research. Nevertheless, if science is nothing more than an extended language game, the human is trapped in a relativist quagmire. Nothing can be known about reality itself in that all meaning is constructed by players of the same language game.

Language games do not exist or function without cause, context and components. For a language game to be played there is a logical requirement that players exist. Additionally, these players need to inhabit a context (Kirk, 1999:102). If a language game cannot be played by a player on his/her own - a game in this context implies 
more than one player - then meanings are shared between players in terms of the language game context which they occupy. Infused within the language game argument is a reality that transcends the playing of the game of which the players are but a component (Kirk, 1999:102). This context includes the limits and boundaries of the game played, a set of meanings shared by players of the game, and entities towards which the shared meanings relate.

Proponents of antirealist language game arguments could retort that the previous argument originates in a culturally-constructed and communally-accepted language game itself (Kirk, 1999:102). However, this does not explain how it is possible that language games can be played within a particular context. The fact that a language game can occur implies that what is real is more than just language games. There are players, contexts, and entities which collectively mean something to players. Moreover, the existence of different language games implies a multilayered reality, rather than a reality limited to consensus within a language game. Language games suggest the existence of a multifarious reality of which the language game is but a part, instead of a reality in which the language game is all that is.

The context within which language games are played - the reality behind the game - can only be grasped without symbols in the attempt to apprehend without distortion. While the sum total of language cannot be reduced to a system of symbolic cognitive representations, language certainly does make use of these in words signifying dimensions of reality which are more than the symbols themselves. The apple is more than an abstract concept independent from an entity, pointing as it does to a real entity. The relative language game that deems understanding as limited to the players of the game, in other words perceiving language as a closed system, is therefore questioned. Apprehension of the real is prevented without a realisation of the evocative nature of language that directs beyond the linguistic system (Spader, 1998). This rule of evocation is a position which, as we have determined, is unacceptable to those who can only find meaning within language (Rorty, 1982:xx), or as St. Anselm (2000:165) who can only find truth in the extrasymbolic.

The human experience as players of language games wherein meaning is partially constructed is still directed beyond the game. One understands what an apple is, not because language represents what an apple is, but because linguistic categories provide access to the object existing externally to the player of a language 
game. One does not, therefore, remain trapped in the representation (cognitive symbol) of the object but through the category experiences it. It is to the reality of the apple that language directs the perceiver through the word-label. Therefore, the human experience of a reality beyond linguistic understanding - of truth beyond perception - impels movement beyond the language game (Spader, 1998).

The argument has been put forward that humans partially cognate through language, which assists in directing beyond the linguistic system towards entities reflected within language. What is the nature of this reality that is to a degree conceived through the window of language? From the Anselmian framework it is fractional truth (as perceived and cognated) and objective truth (ontologically). Truth is related to the perceptual moment in that the signified is evoked by the signifier. If what is signified is related to the developed symbol, knowledge of what exists (signified) comes to the fore in the encounter between perceiver and perceived (what exists) in understanding (Barsalou, 1999:578). ${ }^{22}$ One of language's roles is with other cognitive systems (e.g. sensory, emotive, etc.) - assistance in comprehending being, using symbols as lenses to cognate. Hence, truth is an essential point of discussion for an ontology of language that takes heed of its cognitive role (cf. Botha, 2003:206).

Anselm levels support to the position that understanding is not limited to language, indeed that symbolic representations point to entities transcending the system of symbols. In terms of the preceding discussion, Anselmian ontology - wherein truth is equated with being - does not imply that a symbolic representation cannot contain rectitude (i.e. correct signification), but that rectitude is not founded in the symbol. Hence, the extent of rectitude is not complete due to the symbol being a filtered representation of truth (e.g. words), rather than what is true in the particular entity being what it ought to be. The symbolic representation of the entity in the word symbol and the being of the entity comes to the fore. Anselm directs the reader to a middle ground between two metaphysics:

22 Other dimensions of the linguistic phenomenon are not discounted, for instance language development through dialogue. In this article the focus is upon the role of language in perception and cognition. Thus, while language is socially formed, the beginning of perception for the individual perceiver can lie in the person's use of the socially and biologically formed linguistic entity. The concern is the encounter of the "l" with what is through the mediation of language in the development of cognitive representations. 
realism and subjectivism. What should be argued for is a clarified and filtered realist comprehension where the possibility of partially knowing through symbolic systems is acknowledged, but also where the limits of what can be known as reflective of what is, are discerned as symbol of an entity, not the entity itself.

\section{Apprehending truth in contemplation}

Anselm has argued that, while what is signified may be true, the cause of truth is not in the signifier but in truth itself. If truth is not wholly contained in any particular representation of what is (e.g. in symbolic representations which undergird the linguistic entity) how can truth/being be apprehended by an agent?

In the early twentieth century, the phenomenologist Max Scheler foresaw the advent of language bound arguments (Spader, 2002: 295; cf. also Scheler, 1973:136-145). He proposed that phenomena themselves were not restricted by representational systems but existed independently of human-imposed symbols and categories (Spader, 2002:295).

[The] philosopher, thirsting for the lived-experience of being, will above all seek to drink at the very sources in which the contents of the world reveal themselves. His reflective gaze rests only on that place where lived-experience and its object, the world, touch one another. (Scheler, 1973:138.)

The very sources are the objects themselves, as they are present to the perceiver, unfiltered and raw.

Something can be self-given only if it is no longer given merely through any sort of symbol; in other words, only if it is not 'meant' as the mere 'fulfillment' of a sign which is previously defined in some way or other. In this sense phenomenological philosophy is a continual desymbolization of the world. (Scheler, 1973:143.)

The Schelerian experience is the phenomenological ephoché (Lutz \& Thompson, 2003:38). It is the development and experience of an approach towards reality which is open to the direct presence of being by the awareness and bracketing of the worldviews, which undergird the human encounter with existence in the world (Lutz \& Thompson, 2003:38).

The embodied human being is engaged with the environment and the self through self-reflective consciousness. Western psychologi- 
cal explorations of consciousness describe three conscious states, namely wakefulness, dreaming, and sleeping (Rubia, 2009:2). To this division contemplative traditions add a fourth state of consciousness, namely thoughtless awareness (Rubia, 2009:2). A bias has continued to be evident in the assumption that contemplation is necessarily religious, and thus not relevant to those outside faith traditions. While contemplation can be faith-based as evident in the Hindu, Buddhist, Judaeo-Christian, Sufi, and other faith traditions, it is not necessarily so (De Wit, 1991:17). ${ }^{23}$ Religious or not, contemplation is fundamentally human.

It is argued in some psychological studies that contemplation leads to "thoughtless awareness" in the halting of "... the incessant thinking processes of the mind ..." (Rubia, 2009:2). ${ }^{24}$ In addition to mental silence, contemplation can lead to an awareness - symbolically free - of the embodied state and its context (Rubia, 2009:2). Such insightful understanding has a higher likelihood of occurring when the conscious individual is in the state of mind facilitated by contemplation (Walsh, 2011:120).

A prejudice against contemplation is apparent in psychology, for introspective processes were often discounted as means to obtain scientific accounts of subjective conscious experience (Thompson, 2006). However, as part of what comprises the human experience, scientific pursuits like neurophenomenology place introspection and contemplation (a fruit of introspection) as "... a partner in the scientific investigation of consciousness" (Thompson, 2006:2).

The core concern of psychological studies of contemplation obviously relates to its psychological impact (De Wit, 1991:24). Studies across religious and secular contemplative traditions reveal remarkable similarity in the product of the contemplative process.

23 A secular, poetic interpretation of the contemplative moment was referred to by Alfred Lord Tennyson in his poem The ancient sage:

[F]or more than once when I

Sat all alone, revolving in myself

The word that is the symbol of myself,

The mortal limit of the Self was loosed,

And past into the Nameless, as a cloud

Melts into heavens (Tennyson, 2004:500).

24 Similar studies have been undertaken by West (1987), De Wit (1991), Lutz \& Thompson (2003), Rubia (2009), and Walsh (2011). 
The result is that brief glimpses extend into continuous vision, novel perspectives become permanent metaperspectives, and new insights develop into enduring understandings ... certain functionally specific and higher states may be doorways through which wisdom - in the form of valuable insights, understandings, perspectives and resultant ways of life - can emerge and find expression. (Walsh, 2011:121.)

Contemplatives make an ontological claim that contemplation provides "... insight into the fundamental nature of self and reality ...", unmediated by concepts or cognition (Walsh, 2011:124). It is an awareness of what is without recourse to the categorisation of thoughts into symbolic entities. This awareness is, however, always from the subjective perspective (De Wit, 1991:68-69). As subjective experience there is no general experience that can be deemed contemplative, it being an individual encounter between experience and being (De Wit, 1991:72). However, De Wit (1991:83) argues that it is not primarily knowledge production that the contemplative tradition seeks; instead its focus is on the creation of knowers.

Contemplation is non-conceptual, which differs from meditation (defined as conceptual in the conscious pondering over particular issues, objects, etc.) (De Wit, 1991:84). Scholars argued for syneidesis, referring to "... a way of seeing reality clearly, or seeing the truth without the veil of concepts" (De Wit, 1991:85; cf. also Aquinas, 1920, 1: Summa Theologica, Question 79, Art. 12). Here, knowledge is generated not so much depending on the absence of concepts, but neither with nor without concepts: a stance wherein the real is encountered but not limited in the use of symbols (De Wit, $1991: 86)$. To move beyond symbols, to desymbolise experience, to enter the ephoché

... our thinking must proceed phemenologically, for only then is the world given to us concretely, and without symbols - such as 'sense data', - that may eventually distort our primordial relation to a world, and lead us to conceive of things as they are implied by symbols and metaphors, rather than as they are given to a person (Kelly, 1997:146).

The moment of experience beyond symbolic representation is the "originary moment" when reality is encountered in an unhampered manner (Peeters, 2004). This cannot be expressed symbolically, for when symbols are employed to describe the encounter with reality distance from being arises (Peeters, 2004). A frequent use of the methods of contemplation can assist the perceiver in coming to an 
“... awareness of pure Being ...", an unfettered knowledge of the way things are (West, 1987:13).

This epistemology is different to scientific conceptual modes: objective testing and validity can be readily called into question (Walsh, 2011:124). Yet, contemplation is not scientific and should not be measured against what it does not claim to be (De Wit, 1991:68-69). Even against science, though, neurophenomenological scholars such as Lutz and Thompson (2003:33) point out the fallible nature of perception and cognition in the development of conceptual understandings of what is observed and perceived. Caution is levelled against what can be known, but not against the reality of what is beheld: while the contemplative experience pushes the person to encounter truth, it cautions against binding or restricting the experience in terms of categorisation and symbolic representation, for truth is apart from both.

The earlier work of Wittgenstein (specifically in the Tractatus LogicoPhilosophicus, 1922) - while possible to read in an antimetaphysical manner - supports the principal thesis of this article (Fann, 1971: 26). Wittgenstein (1922:74) states: "The limits of my language mean the limits of my world." The world being for Wittgenstein (1922:25), "... everything that is the case". Hence at first reading, Wittgenstein proposes that what cannot be articulated in language is not the case for the perceiving subject.

Viewed in the light of the Preface to the Tractatus (Wittgenstein, 1922) as well as to subsequent comments, the reading as elucidated above is incorrect. In his exploration of natural language, Wittgenstein delineated statements into three categories, namely those which make sense, those that lack sense, and nonsensical propositions (Formosa, 2007). For the early work by Wittgenstein, it was only propositions that represent actual (or possible) "state[s] of affairs" that make sense (Formosa, 2007). "If a sign is not necessary then it is meaningless", Wittgenstein (1922:36) states. The demarcation between what makes sense and what does not, for Wittgenstein, is the meaning the statement has. And the only manner in which meaning can be determined is to ascertain whether or not the proposition shares commonalities with what "is the case" (Wittgenstein, 1922:25; cf. also Formosa, 2007).

A proposition which cannot be expressed in language has no meaning, for the meaning is found in the language employed: whatever is beyond language "... will be simply nonsense" (Wittgenstein, 1922:23). This statement is founded in the assumption that 
anything describable by using language can be done in a clear manner (Wittgenstein, 1922:23).

In the earlier work by Wittgenstein, language represents the world to those who apprehend it.25 But these facts only tell us "... how the world is" (Wittgenstein, 1922:89). For Wittgenstein the very existence of the world is thus also a matter of importance, which he does not deem to be comprehendible in a sensible fashion through the propositions of science. The weight of the non-sensical, of the symbolically transcendent, comes to the fore towards the end of the Tractatus. "There is indeed the inexpressible. This shows itself: it is the mystical." (Wittgenstein, 1922:90.)

The foundational-metaphysical problem of existence is not sensible to Wittgenstein (1922:26), for linguistically one cannot picture that which is the case in metaphysical propositions. Wittgenstein does not negate the existence of the metaphysical, however, clearly he conceives it to be of paramount importance, despite the non-sensical nature of questions of existence. The Tractatus ends with the frequently quoted words of Wittgenstein (1922:90): "Whereof one cannot speak, thereof one must be silent."

Silence does, however, not imply ignoring the reality encountered. It implies an awareness of the existence of the non-sensical and knowledge of the inability to express that nonsense, which necessarily transcends representation. The early Wittgenstein ends in being, silently - in what can be identified in terms of the above as contemplation.

\section{Conclusion}

The demonstration has been sought that language - as a representational system - leads beyond linguistic confines such that the being of the entities to which language points may be partially grasped. Through language, meaning is afforded to the entities - be they material or introspective experiences. However, these representations do not contain the fullness of the being which they represent. Thus, the argument is made that language limits the

We make to ourselves pictures of facts. The picture presents the facts ... The picture is a model of reality. To the objects correspond in the picture the elements of the picture. The elements of the picture stand, in the picture, for the objects. 
ontology that can be known, proposing instead that contemplative moments of symbol-less attentiveness can provide ontological knowledge in human beings' awareness of being.

Through the realist ontology of Saint Anselm the limits of language as an epistemological instrument were described. This led to the proposition that truth is unexperiencable, but that being/truth should not be closed off to the human being through the sole employment of language. Language does not contain the truth it signifies. It is only a representation of an ontological experience. The task the philosophically inclined are given is to apprehend being/truth despite its inability to be totally contained in any sensible language game.

In transcending representational systems such as language, the human being can bring a part of human perception and cognition into synchronisation with the character of nature: not representative of something, as conceived in any symbolic system, but encountered as that which is. ${ }^{26}$ As the contemplative notes:

How rich are nature's songs, how deep her silence! (De Mello, 1990:324.)

\section{List of references}

ANSELM OF CANTERBURY. 2000. On truth (De Veritate) (In Hopkins, J. \& Richardson, H., eds. Complete philosophical and theological treatises of Anselm of Canterbury. Minneapolis: Banning. p. 164-190.)

AQUINAS, SAINT THOMAS. 1920. Whether syndreses is a special power of the soul distinct from the others? la q. 79 a. 12. http://www.op.org/ summa/letter/summa-lq79a12.pdf Date of access: 1 Aug. 2011.

BARSALOU, L.W. 1999. Perceptual symbol systems. Behavioural and brain sciences, 22:577-660.

BOTHA, R.P. 2003. Unravelling the evolution of language. Amsterdam: Elsevier.

CHOMSKY, N. 1982. The generative enterprise: a discussion with R. Huybregts and H. Van Riemsdijk. Dordrecht: Foris.

DE MELLO, A. 1990. Wellsprings: a book of spiritual exercises. Anand: Gujarat Sahitya Prakash.

Scheler, 1973:145:

Phenomenology has reached its goal when every symbol and halfsymbol is completely fulfilled through the 'self-given', including everything which functions in the natural world-view and in science as a form of understanding (everything 'categorical'); when everything transcendent and only 'meant' has become immanent to a livedexperience and intuition. It has reached its goal at the point where there is no longer any transcendence or symbol. 
DE WIT, H.F. 1991. Contemplative psychology. Pittsburgh: Duquesne University Press.

DILLON, M.C. 1995. Semiological reductionism: a critique of the deconstructionist movement in postmodern thought. Albany: State University of New York.

EVANS, V. \& GREEN, M. 2006. Cognitive linguistics: an introduction. Edinburgh: Edinburgh University Press.

FANN, K.T. 1971. Wittgenstein's conception of philosophy. Berkeley: University of California Press.

FODOR, J.A. 1998. Concepts: where cognitive science went wrong. Oxford: Clarendon.

FODOR, J.A. 2000. The language of thought: first approximations. (In Cummins, R. \& Dellarosa Cummins, D., eds. Minds, brains, and computers: the foundations of cognitive science. Malden: Blackwell. p. 51-68.)

FORMOSA, P. 2007. Saying the unsayable: Wittgenstein's early ethical thought. Sorites: digital journal of analytical philosophy, Dec. http://www.sorites.org/lssue_19/formosa.htm Date of access: 13 Oct. 2011.

KELLY, E. 1997. Structure and diversity: studies in the phenomenological philosophy of Max Scheler. Dordrecht: Kluwer Academic Publishers.

KIRK, R. 1999. Relativism and reality: a contemporary introduction. London: Routledge.

KOHAK, E. 1984. The embers and the stars: a philosophical inquiry into the moral sense of nature. Chicago: University of Chicago Press.

LAKOFF, G. \& JOHNSON, M. 1999. Philosophy in the flesh: the embodied mind and its challenge to Western thought. New York: Basic Books.

LEWIS, C.I. 1929. Mind and the world order: outline of a theory of knowledge. New York: Charles Scribner's Sons.

LUTZ, A. \& THOMPSON, E. 2003. Neurophenomenology: integrating subjective experience and brain dynamics in the neuroscience of consciousness. Journal of consciousness studies, 10(9-10):31-52.

PEETERS, L. 2004. Lecture on Saint Anselm of Canterbury's De Veritate. (Unpublished.)

RORTY, R. 1979. Philosophy and the mirror of nature. Oxford: Blackwell.

RORTY, R. 1982. Consequences of pragmatism: essays 1972-1980. Minneapolis: University of Minnesota Press.

RORTY, R. 1989. Contingency, irony, and solidarity. Cambridge: Cambridge University Press.

RUBIA, K. 2009. The neurobiology of meditation and its clinical effectiveness in psychiatric disorders. Biological psychology, 82:1-11.

SCHELER, M. 1973. Selected philosophical essays. Evanston: Northwestern University Press.

SPADER, P. 1998. Transcending language: the rule of evocation. http://www. bu.edu/wcp/Papers/Lang/LangSpad.htm Date of access: 6 Oct. 2004.

SPADER, P. 2002. Scheler's ethical personalism: its logic, development and promise. New York: Fordham University Press.

TENNYSON, A. 2004. The poetic and dramatic works of Alfred Lord Tennyson. Whitefish: Kessinger.

THOMPSON, E. 2006. Neurophenomenology and contemplative experience. (In Clayton, P. \& Simpson, Z., eds. The Oxford handbook of religion and science. Oxford: Oxford University Press.) http://individual.utoronto. ca/evant/OxfordHanbook.pdf Date of access: 20 Jul. 2011. 
VISSER, S. \& WILLIAMS, T. 2004. Anselm on truth. (In Davies, B. \& Leftow, B., eds. The Cambridge companion to Anselm. Cambridge: Cambridge University Press. p. 204-221.)

WALSH, R. 2011. The varieties of wisdom: contemplative, cross-cultural, and integral contributions. Research in human development, 8(2):109-127.

WEST, M.A. 1987. Traditional and psychological perspectives on meditation. (In West, M.A., ed. The psychology of meditation. Oxford: Clarendon. p. 522.)

WILDER, H.T. 1971. Lewis and Quine on private meaning and subjectivism. Canadian journal of philosophy, 1(1):25-44.

WITTGENSTEIN, L. 1922. Tractatus logico-philosophicus. London: Kegan Paul, Trench, Trubner.

WITTGENSTEIN, L. 1960. The blue and brown books. Oxford: Blackwell.

\section{Key concepts:}

epistemology

language

mysticism

philosophy

religion

\section{Kernbegrippe:}

epistemologie

godsdiens

mistisisme

taal

wysbegeerte 